\title{
Bacteriophage Attachment Sites, Serological Specificity, and Chemical Composition of the Lipopolysaccharides of Semirough and Rough Mutants of Salmonella typhimurium
}

\author{
A. A. LINDBERG AND C. G. HELLERQVIST \\ Department of Bacteriology, Statens Bakteriologiska Laboratorium, and Department of Organic Chemistry, \\ University of Stockholm, Stockholm, Sweden
}

Received for publication 1 October 1970

\begin{abstract}
Extracted lipopolysaccharides (LPS) from one smooth, one semirough, and five rough mutants of Salmonella typhimurium LT2 or LT7, for which the chemical structure of the polysaccharide chain had been elucidated by using methylation analysis, were characterized with passive hemagglutination inhibition and phage inactivation experiments. Each addition of a sugar residue to a LPS from chemotype Rc was reflected in changed serological reactivity and phage-inhibiting activity of a collection of bacteriophages of the isolated LPS. Thus, certain criteria can be established for a classification of rough mutants of $S$. typhimurium. The observation that the serological RII specificity corresponds to a completed common core polysaccharide was verified. The serological RI specificity was found in LPS with terminal D-galactose I residues. One of the mutants, SL733, yielded a LPS which cross-reacted with anti-O5 factor serum although the polysaccharide was virtually free from contaminating $\mathrm{O}$-specific material. The $\mathrm{O} 5$ reactivity was destroyed by alkaline treatment of SL733 LPS. The smooth- and rough-specific Felix O-1 (FO) and the rough-specific $6 \mathrm{SR}$ and $\mathrm{Br} 2$ phages were shown to have their receptors in the LPS. There was a good correlation between the adsorption rate constant to whole cells and the phage inhibiting activity of isolated LPS suggesting that the LPS exert the major influence on the attachment of these phages to the bacteria. The polysaccharide structures in the LPS necessary for attachment of the 6SR and $\mathrm{Br} 2$ phages were defined. It was found that measuring the phage-inhibiting properties of isolated LPS as $\mathrm{PhI}_{50}$ (LPS concentration required to inactivate $50 \%$ of the phages under defined conditions) was a more sensitive method for a characterization of the LPS than the serological and chemical assays used.
\end{abstract}

The lipopolysaccharides (LPS) of Salmonella are known to consist of three different regions: one outer region, the $\mathrm{O}$-specific side chain, composed of polymerized repeating units linked to an inner region, the basal core, which in turn is linked to lipid A (for review, see 14, 16, 17). Mutants defective in the synthesis of the repeating units ( $r f b$ mutants), the polymerization of these units ( $r f c$ mutants), or in the synthesis of the basal core ( $r f a$ mutants) have been used to elucidate the structural features of the polysaccharide part of the LPS.

Studies on LPS isolated from rough (R) mutants resulted in the proposal of a partial structure for the core polysaccharide, suggesting the sequential order of the monosaccharides in a pentasaccharide (25). Some of the linkages were determined as well. In a recent paper, Nikaido (19) demonstrated that the $\mathrm{O}$ side chain is linked to the subterminal glucose of the core polysaccharide and not to $N$-acetyl-D-glucosamine as had been inferred earlier. R mutants of $S$. typhimurium have been further characterized by their sensitivity to a collection of bacteriophages (Wilkinson, Ph.D. Thesis, Univ. of London, London, England, 1966), and by the specificity of isolated LPS in serological tests. No clear-cut relationships between the chemical composition of the common core polysaccharide, its serological specificity, and the sensitivity to bacteriophages could, however, be established when a series of R mutants of $S$. minnesota and $S$. ruiru were studied (13).

We studied six mutants of $S$. typhimurium, and the smooth parent strain $S$. typhimurium LT2, which displayed different phage patterns 
when tested for susceptibility to the phages used by Wilkinson, assuming that the differences in phage sensitivity might be reflected by differences in serological specificity and chemical composition of the core polysaccharide. The LPS isolated from five of the mutants were subjected to a structural analysis using methylation analysis. The results of the chemical investigation, in which the structure shown in Fig. 1 was proposed, will be published elsewhere (Hellerqvist and Lindberg, Carbohyd. Res., in press). The present paper describes the further characterization of the selected mutants of $S$. typhimurium, which included measurement of phage attachment to whole bacteria, determination of the phage-inhibiting capacity of isolated LPS, and the inhibitory effect of the LPS preparations in passive hemagglutination using red cells coated with LPS and homologous antisera.

\section{MATERIALS AND METHODS}

The bacterial strains were derived from $S$. typhimurium. The mutants $\mathrm{SH} 777, \mathrm{SH} 180, \mathrm{SL733}, \mathrm{TV} 160$, and TV148 are derived from $S$. typhimurium strain LT2, whereas the parent strain of SL3994 is S. typhimurium strain LT7. The SH strains came from the collection of P. H. Mäkelä, State Serum Institute, Helsinki, Finland; the SL and TV strains were from the collection of B. A. D. Stocker, Department of Microbiology, Stanford University, Stanford, Calif. The characteristics of the strains are given in Table 1. Each strain was reisolated from a single colony and shown to behave as expected when tested for nutritional characteristics and phage sensitivity before and after cultivation. The bacteria were grown as described earlier (4). The LPS was extracted by the phenol-water procedure (27) from isolated cell walls from the smooth (S) and semirough (SR) strains, and with a mixture of aqueous phenol, chloroform, and petroleum ether (PCP) from ethanol, acetone, and ether-dried bacteria for the $R$ mutants (2).

The serological specificity of the LPS preparations was studied by passive hemagglutination inhibition. The procedure was the same as described by Lindberg and Holme (8). The serum dilutions used were two to eight hemagglutinating units. The hemagglutination systems were chosen to represent the various classes of $\mathbf{R} \mathrm{mu}$ tants as well as the parent strain $S$. typhimurium LT2 (relevant $O$ antigen factors 4,5 , and 12 ).

The bacteriophages used consisted of the S-specific $S$. typhimurium phage P22 (3), the S- and R-specific Salmonella phage FO (Felix O-1), and the R-specific phages $6 \mathrm{SR}, \mathrm{Br} 2$, and $\mathrm{Br} 60$. The phages were obtained through the courtesy of B. A. D. Stocker, Stanford University, Stanford, Calif. They were propagated on the appropriate host strains, and their lytic spectrum was checked on selected $\mathbf{S}$ and $\mathbf{R}$ strains. Some of their properties were described by Wilkinson and Stocker (29). The phage sensitivity of the bacterial strains was tested by spotting drops of phage containing approximately $10^{8}$ plaque-forming units (PFU) per $\mathrm{ml}$ on surface-inoculated nutrient agar plates. The plates were examined after 5 and $18 \mathrm{hr}$ of incubation at $37 \mathrm{C}$. The $\mathrm{Br} 2$ bacteriophage was purified before use to avoid interference with an inhibitor present in the phage lysate (unpublished data). Since the 6SR phage is dependent on the presence of $\mathrm{Ca}^{2+}$ in the medium for attachment and infection (unpublished data), the spot test was also done on $\mathrm{CaCl}_{2}$-supplemented nutrient agar.

The adsorption rate constant (ARC) for the P22, FO, 6SR, and $\mathrm{Br} 2$ bacteriophages was estimated by determination of (i) total attachment and (ii) number of phage-infected bacteria (9). The only modification was that the bacteria were washed in nutrient broth twice and then suspended in salt-supplemented broth to a concentration of about $2 \times 10^{8}$ cells $/ \mathrm{ml}$ before the bacteriophages were added. The concentration of bacteria was estimated by a determination of the total cell count. Optimal attachment of the $\mathrm{FO}$ and $\mathrm{Br} 2$ bacteriophages occurred in nutrient broth (Difco) supplemented with $0.15 \mathrm{M} \mathrm{NaCl}$. For phage 6SR the broth was supplemented with $0.01 \mathrm{M} \mathrm{CaCl}_{2}$. In the determinations of the ARC, by estimation of the number of phage-infected bacteria, antiphage serum was used to neutralize unattached phage (6). The antiphage sera were adsorbed with the corresponding propagating strain so that no agglutination was demonstrated when the serum was diluted 1:10. The $K$ values for the antiphage sera were: phage P22, 46; FO, 890; 6SR, 299, and $\mathrm{Br} 2,320$.

The phage-inhibiting capacity of the LPS preparations was measured as described earlier (7). Activity was expressed as $\mathrm{PhI}_{\mathbf{5 0}}$, the concentration of LPS (micrograms of total hexoses, i.e., anthrone-positive material) per milliliter required to inactivate $50 \%$ of the phages under defined conditions. The anthrone method (28) was used for the determination of the total hexose content of LPS preparations with D-glucose as the standard.

\section{RESULTS}

Table 1 shows the behavior of the parent strain $S$. typhimurium $\mathrm{LT} 2$ and various $\mathrm{SR}(r f c)$ and $\mathrm{R}$ mutants of $S$. typhimurium LT2 och LT7. All R mutants except $S$. typhimurium SH180 were found to have incomplete "leaky" defects in the

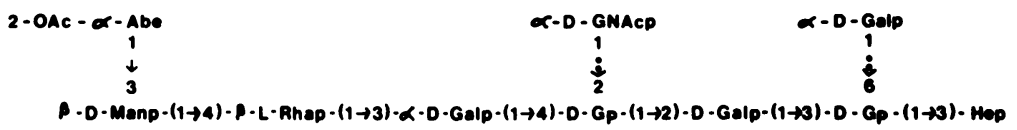

FIG. 1. Proposed chemical structure for the lipopolysaccharide of the semirough mutant strain Salmonella typhimurium SH777 (4). Abbreviations: Hep, heptose; G, glucose; Gal, galactose; GNAc, N-acetyl-glucosamine; Rha, rhamnose; Man, mannose; Abe, abequose; OAc, O-acetyl unit. The dotted line indicates that not all of the sugar residues carry the indicated substituent. The $p$ indicates that all the sugars are in the pyranosidic form. 
TABLE 1. Comparison of smooth, semirough, and rough strains of Salmonella typhimurium

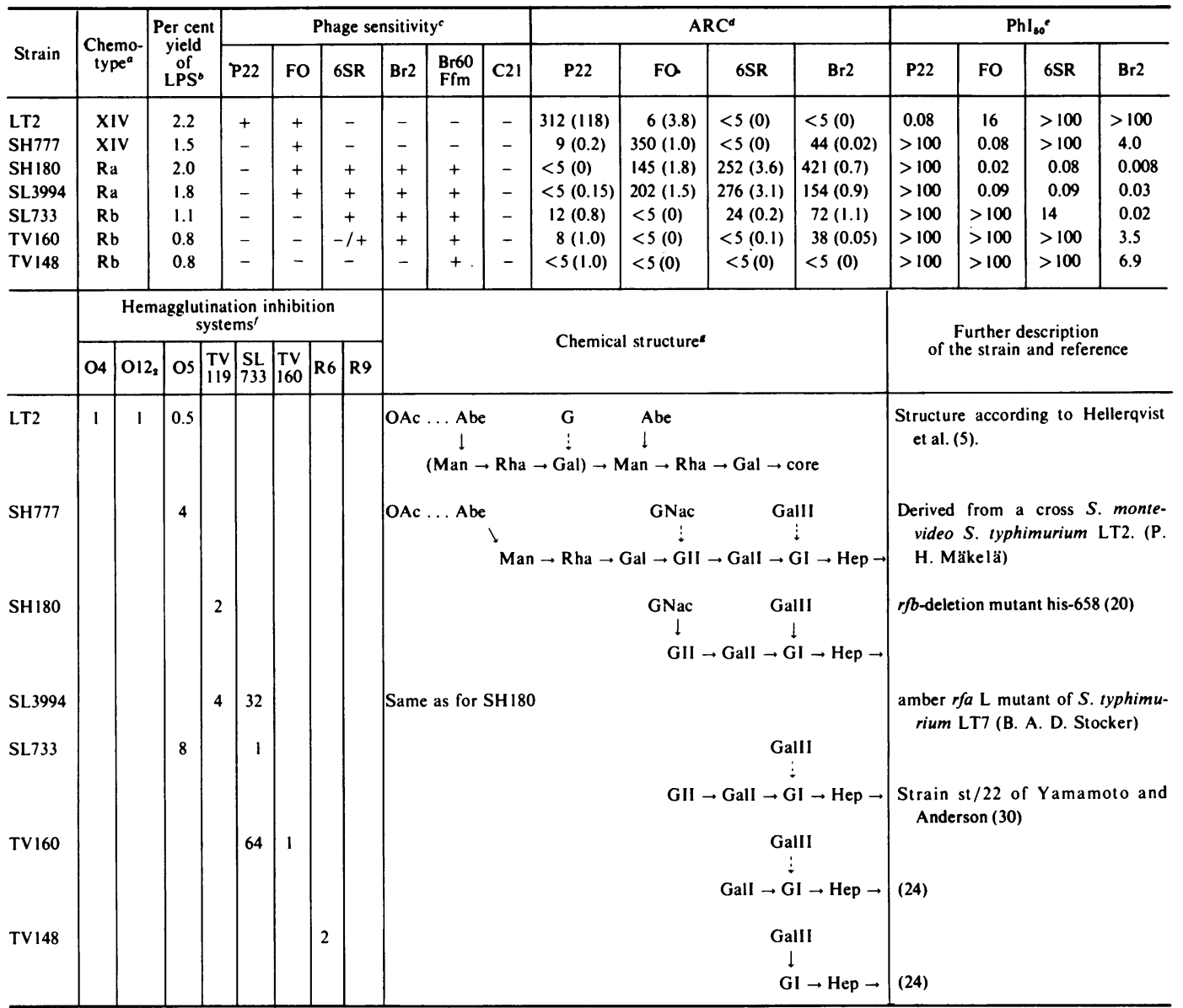

a Nomenclature according to Lüderitz et al. (16)

${ }^{\circ}$ Expressed as per cent by weight of lipopolysaccharides (LPS) of the bacterial mass.

" Determined by the standard method of applying drops of phage $\left(10^{8} \mathrm{PFU} / \mathrm{ml}\right)$ on surface-inoculated nut rient agar plates. The symbol " $-/+$ " indicates lysis only when $\mathrm{Ca}^{2+}$-supplemented nutrient agar was used.

${ }^{a}$ Attachment rate constant (ARC) determined by adding chloroform to the phage and bacterium mixture. This measures total attachment to the bacteria. The figures in parentheses represent the ARC estimated by counting the number of phage-infected bacteria. Values expressed as $10^{-11} \mathrm{ml} / \mathrm{min}$.

- The concentration $(\mu \mathrm{g} / \mathrm{ml})$ of hexoses in the LPS (estimated by the anthrone method with D-glucose as standard) required for inactivation of $50 \%$ of added bacteriophage $\left(2 \times 10^{3} \mathrm{PFU} / \mathrm{ml}\right)$.

I Data recorded on the minimal concentration of LPS [micrograms (dry weight) of LPS $/ \mathrm{ml}$ ] from the strains needed for inhibition of four to eight hemagglutination units of the homologous system. Entries left blank indicate that LPS concentrations higher than $256 \mu \mathrm{g} / \mathrm{ml}$ were needed for the inhibition. O4, O12, and O5 are antigens of the smooth parent strain $S$. typhimurium LT2 of chemotype XIV. The mutant TV119 is of chemotype Ra; the strains SL733, TV160, and R6 represent different mutants of chemotype Rb; st ;ain R9 is of chemotype Rc.

B Proposed chemical structure for the polysaccharide part of the LPS of S. typhimurium (Hellerqvist and Lindberg, Carbohyd. Res., in press). The roman numerals refer to the sequence of addition of the sugar. Abbreviations: OAc, O-acetyl unit; Abe, abequose; G, glucose; ‘Man, mannose; Rha, rhamnose; Gal, galactose; GNac, $\mathrm{N}$-acetyl-glucosamine; Hep, heptose; dotted line, not all of the sugar residues carry the indicated substituent.

mutation leading to roughness. As a result, the LPS of these strains contained various amounts of O-specific sugars, a fact reflected in both serological specificity and sugar analysis of the cell wall LPS. The LPS of all $R$ mutants therefore were extracted with the PCP procedure to avoid contamination with O-specific material (2). The yield of LPS varied between 0.8 and $2.0 \%$ of the bacterial cell mass (dry weight). The yield of LPS from isolated cell walls from the $\mathrm{S}$ strain LT2 and the SR mutant SH777, which were extracted with hot phenol-water, was 1.5 and $2.2 \%$, respectively. The LPS preparations used in the serological and phage experiments were the same as those studied by chemical analysis $(5$, Hellerqvist and Lindberg, Carbohyd. Res., in press).

Strain LT2 showed a S-specific phage pattern, i.e., lysed by the P22 and FO bacteriophages but 
not by any of the R-specific phages. Phage P22 was adsorbed at a high rate and FO to some extent, whereas no measurable attachment of 6SR and $\mathrm{Br} 2$ occurred. The LPS displayed a high P22 and a low FO phage-inhibiting capacity. No inactivation of the $\mathrm{R}$-specific phages in concentrations up to $100 \mu \mathrm{g} / \mathrm{ml}$ was observed. In passive hemagglutination inhibition, 04,05 , and $\mathrm{O}_{2} 2_{2}$ activity was demonstrated.

The SR $(r f c)$ strain SH777 was defective in the polymerase which assembles the repeating units, therefore the $\mathbf{O}$ side chain consisted of only one repeating unit. In spot tests the strain was sensitive only to the FO phage and adsorbed it with a high ARC (350). The measurements of attachment in salt-supplemented broth revealed, however, that the $\mathrm{P} 22$ and $\mathrm{Br} 2$ phages had adsorbed to some extent. Phage $\mathrm{Br} 2$-inhibiting capacity was also demonstrated with isolated LPS. The attachment of the Br2 bacteriophage to SH777 was unexpected since $r f c$ mutants are not sensitive to this phage in spot test. $\mathrm{Br} 2$ attachment to $r f c$ mutants has, however, been observed earlier (11). The SH777 LPS inhibited the O5 factor system, whereas no inhibition of the anti-O4 and anti$\mathrm{O} 12_{2}$ factor systems was observed. The $\mathrm{O} 5$ activity of the LPS is attributed to the O-acetyl located on $\mathrm{C} 2$ of abequose in the repeating unit. Upon mild alkaline hydrolysis the $\mathrm{O}$-acetyl was split off with concomitant disappearance of $\mathrm{OS}$ activity. At the same time inhibition of the anti04 system with $128 \mu \mathrm{g}$ of $\mathrm{LPS} / \mathrm{ml}$ was observed. The lack of $\mathrm{O}_{12}$ activity was in accordance with the observation that no D-glucosyl branch was found on $\mathrm{C} 4$ of the D-galactose residue of the repeating unit.

The two following strains, SH180 and SL3994, displayed a R-sensitive phage pattern. The methylation analyses showed that both strains contained a complete common core polysaccharide with no O-specific sugars present in the LPS. Determination of the ARC revealed that the FO, 6SR, and $\mathrm{Br} 2$ bacteriophages were adsorbed with high rate constants. In addition, measurements of the number of phage-infected cells showed that the mutant SL3994 also adsorbed the P22 phage. Since no revertants could be detected in the batch, the most probable reason for the observed attachment of P22 should be that SL3994 has a leaky defect. For most mutants the ARC values obtained when measured by infective centers were about 100-fold reduced compared to the ARC values for the total attachment measurements. Ospecific sugars were also demonstrated in the sugar analysis performed on a LPS preparation obtained by phenol-water extraction of isolated cell walls. The material that sedimented at $105,000 \times g$ and which did not show any adsorp- tion at $260 \mathrm{~nm}$ had a mannose + rhamnose to heptose ratio of 0.3 . This material also showed serological $\mathrm{O}$ reactivity. $\mathrm{PhI}_{\mathbf{s 0}}$ determinations on the LPS extracted with the PCP procedure showed that both SH180 and SL3994 yielded LPS preparations with a high phage-inhibiting capacity. The $\mathrm{PhI}_{50}$ concentrations for the FO, $6 \mathrm{SR}$, and $\mathrm{Br} 2$ phages were less than $0.09 \mu \mathrm{g} / \mathrm{ml}$. In passive hemagglutination inhibition both LPS inhibited the homologous TV119 LPS/antiserum system (24), the concentrations for complete inhibition were 2 and $4 \mu \mathrm{g} / \mathrm{ml}$, respectively. The LPS preparations also inhibited the homologous LPS/antiserum systems for SH180 and TV 163 (8) in equal concentrations. The LPS from SL3994 cross-reacted with the homologous SL733 system.

Strain SL733 had lost the FO sensitivity and displayed a phage pattern which was recognized as stt-i by Wilkinson (Ph.D. Thesis, Univ. of London, England, 1966). The methylation analysis revealed that this mutant lacked the terminal $N$-acetyl-D-glucosamine of the common core polysaccharide, the polysaccharide chain ending with the D-glucose II residue. The ARC for the 6SR phage to SL733 was found to be lower than to the SH180 and SL3994 mutants. This difference was also evident in the $\mathrm{PhI}_{50}$ determination, the concentration of SL733 LPS required for 6SR inhibition was 100-fold higher. Bacteriophage $\mathrm{Br} 2$ attached to SL733 with a lower ARC than to SH180 and SL3994, whereas the phage-inhibiting capacity of the LPS was high. The lack of the terminal amino sugar in the core polysaccharide apparently made the bacteria resistant to the FO phage since neither attachment to whole cells nor inactivation by isolated LPS could be demonstrated. The presence of $\mathbf{O}$-specific side chains was demonstrated by the attachment of the P22 phage. No smooth revertants were detected in the batch. In passive hemagglutination inhibition, the LPS of this strain failed to inhibit any of the serological systems tested previously (8). The homologous SL733 system was inhibited by its own LPS, but cross-reacted with the LPS of SL3994 and TV160. Although the LPS preparation obtained by the PCP procedure did not contain any demonstrable $\mathrm{O}$-specific sugars (less than $0.3 \%$ of detected sugars), a significant inhibition of the anti-O5 factor system was observed. This finding demonstrated the presence of structures crossreacting with $2-\mathrm{O}$-acetyl- $\alpha$-abequosyl groups in this LPS (4). An alkali-treated preparation of SL733 did not inhibit the anti-O5 factor system. The chemical basis of the O5 reactivity of SL733 LPS remains to be established.

The next mutant strain, TV160, had lost the 6SR sensitivity when tested on nutrient agar; the 
phage pattern was termed $R$ resistant-1. If the spot test were performed on $\mathrm{Ca}^{2+}$-supplemented agar, this strain was lysed by the 6SR phage. Chemical analyses showed that this mutant lacked the D-glucose II residue, the polysaccharide chain ending with the terminal D-galactose I and D-galactose II residues. The phage adsorption measurements revealed that only a limited attachment of the $\mathrm{Br} 2$ phage occurred. In accordance with this, the isolated LPS had a low $\mathrm{Br} 2$ phage-inhibiting capacity, the amount required $(3.5 \mu \mathrm{g} / \mathrm{ml})$ was more than 100 -fold higher than for the three other $\mathbf{R}$ mutants discussed. The observed P22 attachment to the bacteria was probably because the TV160 strain is "leaky." Serologically, the LPS inhibited the homologous TV160 system as well as other representatives of the RI system (8).

Strain TV148 displayed a $R$ resistant-2 phage pattern, which means that it was lysed only by the Br60 and Ffm bacteriophages. This strain has a leaky mutation too, as a measurable adsorption of P22 was observed when assaying for phageinfected cells. No attachment was detected by any method for the FO, 6SR, and $\mathrm{Br} 2$ bacteriophages. The $\mathrm{Br} 2$ phage, however, was inactivated to $50 \%$ by $6.9 \mu \mathrm{g}$ of the TV148 LPS per ml. Structurally, the polysaccharide chain of this mutant is built by D-galactose II linked to C6 of D-glucose I. The LPS inhibits the homologous $S$. typhimurium 395MR6 LPS/antiserum systems as well as it inhibits the homologous TV148 system. The R6 system was also inhibited by 5 $\mu$ moles of the synthetic disaccharide melibiose ( $\alpha$ galactose 1,6-glucose), whereas no inhibition could be demonstrated with $20 \mu$ moles of lactose ( $\beta$-galactose 1,4-glucose). The LPS did not show any cross-reactions with the other hemagglutination systems tested in concentrations up to 256 $\mu \mathrm{g} / \mathrm{ml}$, nor did it inhibit the homologous R9 system which is representative for mutants of chemotype Rc (8).

\section{DISCUSSION}

The data presented show that there exists an obvious correlation between the phage sensitivity, serological specificity, and chemical structure of the common core polysaccharide of the cell wall LPS in $\mathbf{R}$ mutants of $S$. typhimurium. Starting from the structure of a LPS with only D-glucose I linked to the heptose residue (chemotype $\mathrm{Rc}$ ), each addition of a monosaccharide is reflected in a changed specificity both in the sensitivity to certain bacteriophages, and in serological specificity of the LPS in passive hemagglutination inhibition. Such a subdivision of various mutants has not been achieved earlier, probably due to the lack of structural studies on the three possible classes of chemotype $\mathbf{R b}$ mutants. Certain criteria can thus be established for a classification of $\mathrm{R}$ mutants of $S$. typhimurium.

Information about the sequence of the monosaccharides in the common core polysaccharide had previously been obtained in studies on the biosynthesis of the core (22), whereas some of the linkages had been determined by graded hydrolysis of the LPS followed by the isolation and identification of oligosaccharides (25). The LPS used in the hydrolysis experiments were derived from mutants showing the serological $R I$ and RII specificities $(1,12)$. The main features of the structure proposed in Fig. 1 verifies what was earlier known about the structure of the outer pentasaccharide of the common core polysaccharide $(13,15,22,25)$, but it is more detailed with respect to some linkages. The nonstoichiometrical amounts of the D-galactose II and $\boldsymbol{N}$-acetyl-D-glucosamine substituents and the presence of alkali-labile groups linked to the monosaccharides, however, was not observed earlier. The chemical data together with the serological tests of this communication established that the RII specificity corresponds to a completed core polysaccharide and the RI specificity to a polysaccharide ending with the D-galactose I residue (Fig. 1), not with the D-glucose II residue as had been proposed (25).

The LPS isolated from the SR mutant SH777 neither inhibited the anti-O4 nor the anti-O12, factor system in passive hemagglutination inhibition. Immunochemical studies have revealed that the $\alpha$-linked abequosyl residue is the immunodominant sugar of $O$ factor 4 (23). The fact that no inhibition was observed with $256 \mu \mathrm{g}$ of SH777 LPS per $\mathrm{ml}$, although a deacetylated preparation showed weak inhibitory properties, suggests that abequose on only one repeating unit is not sufficient for reaction with anti-04 antibodies. Presumably, part of the second repeating unit is necessary.' The presence of $\mathrm{O}$-acetyl groups on abequose in the SH777 LPS, however, was sufficient to cause an inhibition of the anti-O5 factor system. D-Glucose linked to C4 of D-galactose in the repeating unit has been shown to be the immunodominant sugar of $\mathrm{O}$-antigen $12_{2}(26)$. This antigenic specificity may or may not be present in $S$. typhimurium strains. Where present, not all Dgalactose residues carry the D-glucose substituent, the percentage of substitution varied between 8 and 48 in two investigated strains $(4,5)$. The SR mutant did not contain any D-galactose residues substituted at $\mathrm{C} 4$ as revealed by the methylation analysis (Hellerqvist and Lindberg, Carbohyd. Res., in press). This was explained by the observation that the D-galactose of the first re- 
peating unit of the $O$ side chain is $\beta$-linked to the core, whereas all other D-galactose residues are $\alpha$ linked (G. Hämmerling, $O$. Lüderitz, and $\mathbf{O}$. Westphal, Eur. J. Biochem., in press). Since the D-glucose transferring enzyme is expected to be specific for an $\alpha$-linked D-galactosyl acceptor, no glucosylation should occur in the SH777 mutant where the galactose residue is $\beta$-linked.

The mutants SH180 and SL3994 showed the same phage pattern and yielded LPS with the same specificity (for SL3994, unpublished chemical data). Also in the methylation analysis, the polysaccharides proved to be identical. SH180 is a mutant which has deletions in the his operon extending into the $r f b$ gene cluster, causing the loss of several of the enzymes involved in nucleotide-sugar synthesis (20). SL3994 is mutated in the $r f a$ gene cluster. Like other $r f a$ mutants and unlike $r f b$ mutants, it accumulates the O-antigenic hapten (B. A. D. Stocker, personal communication). Although the mutants had their defects in different gene clusters, the resulting phenotypes were shown to be identical.

Strain SL733 yielded a LPS which in passive hemagglutination inhibition neither reacted with the RII nor with the RI serological system. The chemical data indicated that the defect concerns the $N$-acetyl-D-glucosamine LPS transferase. This mutant is rather leaky; the LPS extracted from cell walls by the phenol-water method contained approximately 0.50 -specific repeating units per core stub (11). The SL733 mutant was investigated by Naide et al. (18), who found that its phenol-water-extracted LPS cross-reacted strongly with anti-RII serum in complement fixation test. No cross-reactions with anti-RII systems were observed with the SL733 LPS preparation used in the present work which was obtained by extraction of the bacteria by the PCP procedure (2). Except for the serological $O$ specificity of the phenol-water-extracted LPS (11), both preparations were identical in passive hemagglutination inhibition and phage-inactivating experiments.

From partial hydrolysates of RI LPS, it was suggested that a mutant with the serological RI specificity lacks the $N$-acetyl-D-glucosamine of the core polysaccharide and thus should be deficient in the amino sugar transferase (25). The mutant with RI specificity studied here, TV160, was found to lack not only the amino sugar but also the D-glucose II residue.

The structure of the polysaccharide chain of TV148 with D-galactose II linked to C6 of D-glucose $I$ is identical to that proposed for the galactosyl I transferase-negative mutants SL1033 and SL1060 (21, 29). However, SL1033 and SL1060 were sensitive to the phages $\mathrm{Br} 2$ and $\mathrm{C} 21$, whereas TV148 was resistant. A subculture of the strain of TV148 was resistant to the Br2 and C21 phages also when tested by B. A. D. Stocker (personal communication). Support for the proposed TV148 polysaccharide structure was obtained by the observation that the disaccharide melibiose inhibited the same passive hemagglutination inhibition system as the TV148 LPS did. The mutation leading to roughness is, however, leaky since the P22 phage attached to TV148 bacteria.

Further proof of the proposed structures of the three chemotype Rb mutants studied, SL733, TV160, and TV148, could be obtained by testing for (i) the $\boldsymbol{N}$-acetyl-D-glucosamine, D-glucose II, and D-galactose I LPS transferase activities of the mutants and (ii) the ability of their isolated LPS to act as acceptors for the nucleotide-sugars in biosynthetic experiments.

In the methylation analysis on the fully acetylated polysaccharides of the SH777 and SL733 mutants alkali-labile groups were demonstrated (Hellerqvist and Lindberg, Carbohydr. Res., in press). In $\mathrm{SH} 777$, these groups were linked to $\mathrm{C} 2$ in the abequose and the D-glucose residues; in the SL733 polysaccharide, they were linked to C2 in D-glucose and C4 in D-galactose residues. The structural significance of these findings, except for the $\mathrm{O}$-acetyl linked to $\mathrm{C} 2$ of the abequose residue, remains to be elucidated. It must be stressed, however, that the passive hemagglutination inhibition test using red blood cells coated with alkali-treated LPS does not reveal the eventual immunological significance of these alkalilabile groups.

From ARC determinations, it appears that the access of the FO phage to its receptor is blocked by the long $\mathrm{O}$ side chains in the parent strain $S$. typhimurium LT2, whereas the one repeating unit in a SR mutant does not constitute a hindrance. The $\mathrm{R}$-specific bacteriophages, $6 \mathrm{SR}$ and $\mathrm{Br} 2$, seem to be even more susceptible to interference by $O$ side chains (11). Even the single repeating unit in the SR mutant greatly reduced the accessibility to the respective receptors as measured by attachment rate. There was a good correlation between the ARC measurements (total attachment) and the phage inhibition determinations; a high ARC with bacteria was followed by a high phage-inhibiting capacity of the isolated LPS and a low ARC by a LPS with a low phage-inhibiting capacity. However, exceptions to this statement are expected to be found, the more "leaky" the mutation is, leading to roughness. The completed $O$ side chains will then interfere with the attachment of the FO, 6SR, and $\mathrm{Br} 2$ bacteriophages to whole bacteria, whereas this interference will not be observed in the $\mathrm{PhI}_{50}$ determinations on PCP-extracted LPS. The interaction between Br2 and SL733 whole cells and LPS is 
an example of this. The good agreement between the adsorption rate determinations to whole bacteria and the phage-inhibiting capacity of the LPS indicates that the LPS is the only cell surface structure that exerts any significant influence on the FO, 6SR, and $\mathrm{Br} 2$ phage attachment processes.

The attachment rates were estimated in saltsupplemented broth under optimal conditions for the FO, 6SR, and Br2 bacteriophages. The LPS preparations, however, are precipitated with the concentration of $\mathrm{CaCl}_{2}$ found optimal for $6 \mathrm{SR}$ phage attachment. Since no precipitation occurred in phosphate-buffered saline, in which the $\mathrm{NaCl}$ concentration for $\mathrm{FO}$ and $\mathrm{Br} 2$ attachment was optimal, this medium was used throughout in the $\mathrm{PhI}_{50}$ determinations. The $\mathrm{PhI}_{50}$ values reported for 6SR thus are not obtained under optimal attachment conditions. Characterization of a LPS by its $\mathrm{PhI}_{50}$ value is a sensitive method for evaluating those preparations; the concentrations needed to inhibit $50 \%$ of the phages investigated varied between 0.05 and $0.66 \mu \mathrm{g}$ of $\mathrm{LPS} / \mathrm{ml}$.

Generally, the ARC values obtained by measuring either total attachment or the number of phage-infected cells differed. The total attachment values were about 100 -fold higher. This means that only a fraction of the phages that attach to the cells under the experimental conditions evoke a lytic cycle.

The S-specific P22 bacteriophage attached with a high ARC to the $S$ parent strain S. typhimurium LT2. Attachment was noted to all other strains studied, except the $r f b$ deletion mutant SH180; the rate constants obtained, however, were low. None of these mutants were lysed by the P22 phage in spot test. The most probable reason for the observed $P 22$ attachment is that the mutations in these strains are "leaky." Most side chains in these strains are stopped at the site of the block in the core polysaccharide but some are completed yielding the full $\mathrm{O}$ side-chain complement fulfilling the requirements of the P22 receptor. The P22 attachment to the SR mutant SH777 can also be explained by the presence of $r \mathrm{fc}^{+}$revertants in the adsorption batch of this strain. The phenol-water-extracted LPS preparation of strain LT2 also showed a high phage-inhibiting capacity. It is to be noted, however, that not all LPS preparations of LT2 or other $S$. $t y$ phimurium strains show P22-inhibiting capacity. Extraction with either a $0.02 \mathrm{M}$ phosphate buffer at $p \mathrm{H} 7.2$ at $68 \mathrm{C}$ for $25 \mathrm{~min}$ or $0.25 \mathrm{M}$ trichloroacetic acid at $4 \mathrm{C}$ for $3 \mathrm{hr}$ yield protein-LPS preparations from smooth $S$. typhimurium strains which invariably show P22 phage-inhibiting properties.

As has been shown earlier, the $S$ - and $R$-specific FO phage has its receptor in the LPS, the terminal $N$-acetyl-D-glucosamine of the common core polysaccharide being essential for the receptor activity of the bacteria and the $\operatorname{LPS}(7,9)$. The attachment rate to the SR mutant (SH777) and to mutants containing the terminal amino sugar was high. No FO attachment to the other mutants could be demonstrated by any method. The "leaky" mutants do contain terminal $\mathbf{N}$-acetyl-D-glucosamine residues, since a completed core is a prerequisite for the attachment of the $O$ specific side chains. The amount of terminal amino sugars in these mutants does not, however, suffice to fulfill the requirements for FO attachment under the experimental conditions.

The 6SR and $\mathrm{Br} 2$ bacteriophages are both small, tailless icosahedral phages with large capsomers (unpublished data). No definite conclusions about the structure of the attachment sites could be obtained for any of the bacteriophages. Several of the $\mathbf{R}$ mutants were lysed by both phages but nevertheless great differences in ARC and $\mathrm{PhI}_{50}$ values were observed between the mutants. Obviously, the structure of the polysaccharide side chain of the LPS molecule determines the receptor activity of the LPS for the 6SR and $\mathrm{Br} 2$ phages as it does for the $\mathrm{P} 22$ and FO phages. As judged from the $\mathrm{PhI}_{\mathrm{so}}$ values, the phage-inhibiting measurements are more sensitive than the serological and chemical assays used. This can explain attachment to and inactivation of the $\mathrm{Br} 2$ bacteriophage by the LPS of the SR mutant SH777. Optimal attachment of this phage takes place to a LPS structure where the polysaccharide side chains terminate with either D-glucose II (SL733) or $N$-acetyl-Dglucosamine residues (SH180 and SL3994). Within the limits of the serological and chemical methods used, all core stubs in the SH777 LPS are capped by repeat units but some might be left free and accessible to the $\mathrm{Br} 2$ phage. The highest ARC and phage-inhibiting activity for the 6SR bacteriophage was seen in mutants where the polysaccharide side chains terminate with $N$-acetyl-D-glucosamine (SH180 and SL3994). For both the $6 \mathrm{SR}$ and the $\mathrm{Br} 2$ bacteriophages, low ARC values and low phage-inhibiting activity was observed in mutants (TV148 and TV160) in which the block affects early steps in core biosynthesis (Table I). Several reasons can account for the low but observable activity: (i) presence of "leaky" products in the LPS, i.e., serologically and chemically undetected D-glucose II or $\mathbf{N}$-acetyl-D-glucosamine residues, or both, in these mutants; (ii) the specificity of each phage is broad enough not to require terminal D-glucose II or $N$-acetyl-D-glucosamine residues, or both, for attachment; and (iii) groups in the polysaccharide side chains of the TV148 and TV160 mutants might serve as weak $6 \mathrm{SR}$ and $\mathrm{Br} 2$ sites. 
It is impossible from the data available to favor any of the suggestions.

\section{ACKNOWLEDGMENTS}

The skilled technical assistance of Gunnel Ljunggren is acknowledged. This work was supported by grants from the Swedish Medical Re. search Council (B 69-40X-656-04A to A.A.L. and B 69-13X-2522-01 to C.G.H.), from the Swedish Natural Research Council, from Harald Jeanssons Stiftelse, and from Stiftelsen Sigurd och Elsa Goljes minne.

\section{LITERATURE CITED}

1. Beckman, I., O. Lüderitz, and O. Westphal. 1964. Zur Immunchemie der somatischen Antigene von Enterobacteriaceae. IX. Serologische Typisierung von Salmonella-R-Antigenen. Biochem. Z. 339:401415.

2. Galanos, C., O. Lüderitz, and O. Westphal. 1969. A new method for the extraction of $R$ lipopolysaccharides. Eur. J. Biochem. 9:245249.

3. Gemski, P.. Jr., and B. A. D. Stocker. 1967. Transduction by bacteriophage P22 in nonsmooth mutants of Salmonella typhimurium. J. Bacteriol. 93:1588-1597.

4. Hellerqvist, C. G., B. Lindberg, S. Svensson, T. Holme, and A. A. Lindberg. 1968. Structural studies on the O-specific side-chains of the cell-wall lipopolysaccharide from Salmonella typhimurium 395MS. Carbohyd. Res. 8:43-55.

5. Hellerquist, C. G., B. Lindberg, S. Svensson, T. Holme, and A. A. Lindberg. 1969. Structural studies on the O-specific side-chains of the cell-wall lipopolysaccharide from Salmonella typhimurium LT2. Carbohyd. Res. 9:237 241.

6. Hershey, A. D., and H. Davidson. 1951. Allelic and nonallelic genes controlling host specificity in a bacteriophage. Genetics 36:667-675.

7. Lindberg. A. A. 1967. Studies of a receptor for Felix O-1 phage in Salmonella minnesota. J. Gen. Microbiol. 48:225-233.

8. Lindberg, A. A., and T. Holme. 1968. Immunochemical studies on cell-wall polysaccharides of rough mutants of Salmonella typhimurium. J. Gen. Microbiol. 52:55-65.

9. Lindberg, A. A., and T. Holme. 1969. Influence of $O$ side chains on the attachment of Felix O-1 phage to Salmonella bacteria. J. Bacteriol. 99:513-519.

10. Lindberg, A. A., T. Holme, C. G. Hellerqvist, and S. Svensson. 1970. Bacteriophage receptor development and synthesis of O-specific side-chains after addition of D-galactose to the uridine diphosphogalactose-4-epimeriaseless mutant Salmonella typhimurium LT2M1. J. Bacteriol. 102:540-547.

11. Lindberg, A. A., M. Sarvas, and P. H. Mäkelä. 1970. Bacteriophage attachment to the somatic antigen of Salmonella. Effect of O-specific structures in leaky $R$ mutants and $S$, TI hybrids. Infec. Immun. 1:88-97.

12. Lüderitz, O., I. Beckmann, and O. Westphal. 1964. Zur Immunchemie der somatischen Antigene von Enterobacteriaceae. X. Rspezifische Structuren in Salmonella-O-Antigenen. Biochem. Z. 339:416-435.
13. Lüderitz, O., C. Galanos, H. J. Risse, E. Ruschmann, S. Schlecht, G Schmidt, H. Schulte-Holthausen, R. Wheat, O. Westphal, and J. Schlosshardt. 1966. Structural relationships of Salmonella $O$ and $R$ antigens. Ann N. Y. Acad. Sci. 133:349-374.

14. Lüderitz, O., K. Jann, and R. Wheat, 1968. Somatic and capsular antigens of gram-negative bacteria. Comprehensive Biochem. $26 \mathrm{~A}$ : 105-228.

15. Lüderitz, O., H. J. Risse, H. Schulte-Holthausen, J. L. Strominger, I W. Sutherland, and O. Westphal. 1965. Biochemical studies of the smooth-rough mutation in Salmonella minnesota. J. Bacteriol. 89: 343-354.

16. Lüderitz, O., A. M. Staub, and O. Westphal. 1966. Immunochemistr of $O$ and $R$ antigens of Salmonella and related Enterobacteriaceae. Bacteriol. Rev. 30:192 255 .

17. Mäkelä, P. H., and B. A. D. Stocker. 1969. Genetics of polysaccha ride biosynthesis. Ann. Rev. Genet. 3:291-322.

18. Naide, Y., H. Nikaido, P. H. Mäkelä, R. G. Wilkinson, and B. A. D. Stocker. 1965. Semirough strains of Salmonella. Proc. Nat. Acad. Sci. U.S.A. 53:147-153.

19. Nikaido, H. 1969. Structure of cell wall lipopolysaccharide from Salmonella typhimurium. I. Linkage between $O$ side chains and $R$ core. J. Biol. Chem. 244:2835-2845.

20. Nikaido, H., M. Levinthal, K. Nikaido, and K. Nakane. 1967. Ex tended deletions in the histidine-rough-B region of the Salmonella chromosome. Proc. Nat. Acad. Sci. U.S.A. 57:1825 1832

21. Osborn, M. J. 1968. Biochemical characterization of mutants of Salmonella typhimurium lacking glucosyl or galactosyl lipopolysaccharide transferases. Nature (London) 217:957-960

22. Osborn, M. J., S. M. Rosen, L. Rothfield, L. D. Zeleznick, and B. I Horecker. 1964. Lipopolysaccharides of the gram-negative cell wall Science 145:783-789.

23. Staub, A. M., R. Tinelli, O. Lüderitz, and O. Westphal. 1959. Etude immunochimique sur les Salmonella. V. Rôle de quelques sucres, et en particulier des 3-6 didésoxyhexoses, dans la spécificité des antigénes $O$ du tableau de Kauffmann-White. Ann. Inst. Pasteur 96: 303-332.

24. Subbaiah, T. V., and B. A. D. Stocker. 1964. Rough mutants of Salmonella typhimurium. I. Genetics. Nature (London) 201:1298 1299.

25. Sutherland, I. W., O. Luideritz, and O. Westphal. 1965. Studies on the structure of lipopolysaccharides of Salmonella minnesota and Sal monella typhimurium R strains. Biochem. J. 96:439 448.

26. Tinelli, R., and A. M. Staub. 1960. Analyse de l'antigène $O_{12}$ du tableau de Kauffmann-White. Bull. Soc. Chim. Biol. 42:583 599.

27. Westphal, O., O. Lideritz, and F. Bister. 1952. Uber die Extraktion von Bakterien mit Phenol/Wasser. Z. Naturforsch. 7b:148 155

28. Whistler, R. L., and M. L. Wolfrom. 1962. Methods in carbohydrate chemistry. I. Analysis and preparation of sugars. Academic Press Inc., New York.

29. Wilkinson, R. G., and B. A. D. Stocker. 1968. Genetics and cultural properties of mutants of Salmonella typhimurium lacking glucosyl or galactosyl lipopolysaccharide transferases. Nature (London) 217: 955-957.

30. Yamamoto, N., and T. F. Anderson. 1961. Genomic masking and recombination between serologically unrelated phages $P_{22}$ and P221. Virology 14:430-439. 